\title{
FLUORIDE RELEASE AND RECHARGE BEHAVIOR OF BIOACTIVE GLASS IONOMER CEMENTS USING ION CHROMATOGRAPHY
}

\author{
Asmaa Mohamed Abdallah*, Tamer Mohamed Elshehawy* and Hamada Mohamed Ibrahim**
}

\begin{abstract}
Objective: To evaluate fluoride release and uptake behaviors of the new bioactive resin modified glass ionomer cement (RMGIC) (activa bioactive glass ionomer) compared to conventional glass ionomer cement(CGIC) (Fuji IX GP).

Material and Methods: Forty specimens were prepared (10 mm x $2 \mathrm{~mm}$ ) from Fuji IX GP glass ionomer and Activa Bioactive RMGI according to manufacturer's instructions. The specimens stored in deionized water and fluoride release were assessed daily in the first week then weekly till the third week using ion chromatography. The specimens of each material were divided into two equal subgroups according to the recharging agents used; either $0.05 \%$ mouth wash $(226 \mathrm{ppm}$ sodium fluoride, G.U.M, Sunstar, Germany, GmbH) or $5 \%$ sodium fluoride varnish $(22.600 \mathrm{ppm}$ fluoride, enamel pro varnish Premier Dental, Plymouth Meeting, PA,19462,USA). Fluoride release after recharge was measured and recorded daily for a total of 5 days. Data were analyzed by Two way ANOVA and Duncans test $(\alpha=0.05)$ using the SPSS software program.

Results: CGIC release higher amount of fluoride than RMGIC. Professionally applied fluoride varnish showed better recharging ability than home care fluoride mouth wash and CGIC had greater recharge ability than new RMGIC.
\end{abstract}

KEYWORDS: Fluoride, resin-modified glass ionomer, glass ionomer and recharge

\section{INTRODUCTION}

A bioactive material defined by Hench In 1969 as one that produce a biological response at the interface of the material which resulting in formation of a bond between the tissues and the material, ${ }^{(1)}$ so bioactive materials have the ability to interact with living tissues or system. Depending on previous definition; glass ionomer cements(GICs) are considered bioactive dental materials due to their dynamic release of fluoride, their mineralbased poly-salt matrix composition that contribute to the ability to remineralize tooth structure, their bonding ability to tooth structure and proved biocompatibility. ${ }^{(2)}$ 
GICs materials were invented by Wilson and Kent in $1969 .{ }^{(3)}$ These materials are water-based, known as polyalkenoate cements. It composed mainly of fluoro-alumino-silicate glass and polyalkenoic acid. The setting reaction is an acid/base reaction. GICs materials combine the strength, rigidity, and fluoride release properties of silicate glass powder with the biocompatibility and adhesive characteristics of polyacrylic acid liquid. ${ }^{(4)}$ Despite the proved advantages of GICs (as ion exchange adhesion with tooth structure, ${ }^{(5)}$ fluoride release ${ }^{(6)}$, coefficient of thermal expansion and contraction close to tooth structure $^{(7,8)}$ and biocompatibility ${ }^{(9)}$, they have many disadvantages as moisture sensitivity and lack of sufficient strength. ${ }^{(10)}$ Several modifications of GICs have been done in an effort to overcome these disadvantages.

One of these modifications is the RMGIC which was introduced in the late 1980s to overcome moisture sensitivity, low physical properties (early mechanical strength), and short working time of CGICs. RMGIC are glass-ionomer cements with small quantity of monomers and initiators so the acid-base reaction is supplemented by a second polymerization reaction. ${ }^{(11)}$ Activa BioactiveRestoratives are recently introduced as the first bioactive composite with an ionic resin matrix, resin component and fillers which simulates properties of natural teeth. It is a RMGIC that has the ability to releases and recharges different ions such as calcium, phosphate and fluoride ions. The manufacturer claimed that the hydrophilic resin may provide better fluoride release and uptake than conventional glass ionomer. ${ }^{(12)}$

Progression or control of dental caries depends on the balance between caries process and protective factors. The best method for caries management is remineralization. ${ }^{(13,14)}$ Fluoride is an anti-cariogenic agent, as it is well documented to decrease the tooth demineralization, increase the remineralization, interfere with pellicle and plaque formation, and inhibit microbial growth and metabolism. Fluoride also forms the more acid-resistant fluorapatite instead of carbonated hydroxyapatite. ${ }^{(15)}$ Several clinical studies demonstrated the effects of fluoridated restorative materials on management of dental caries and they reported that fluoride with levels of 0.095 to $0.190 \mathrm{ppm}$ in the saliva for long time may be sufficient for cariostasis. ${ }^{(16-18)}$

To achieve the goal of caries prevention, there must be a constant supply of low levels of intraoral fluoride. Maintenance of Saliva fluoride level from 0.001 to $0.005-0.010 \mathrm{mmol} / \mathrm{l}$, may be efficient for caries control. ${ }^{(19)}$ Fluoride leached out of fluoride containing dental materials decreased over time so fluoride charging is used to sustain constant levels of fluoride. The ability of a restorative material to take and release fluoride is dependent on intrinsic factors (type and permeability of filling material, fluoride content, and nature of fluoride incorporated) and environmental factors (frequency of fluoride exposure and the kind and concentration of the fluoridating agent)..$^{(20,21)}$

GIC and their derivatives not only release fluoride but also act as a fluoride reservoir. ${ }^{(22)}$ The recharging power of glass ionomer cements was first detected by Walls. ${ }^{(23)}$ Many theories explained the recharge mechanism. Dewitte et al. postulated two different mechanisms of recharge; the first is short term release, where fluoride ions simply diffused out through the cement matrix. The second is long term release, where fluoride ions reacting with the intrinsic ions in the matrix, re-released again decomplexation. (24) Diaz-Arnold and co-workers described recharging as surface phenomenon, where the adsorbed fluoride ions to the surface of the restoration get washed off. ${ }^{(25)}$ Recharging agents include; fluoridated dentifrices, mouth rinses, fluoride gels and fluoride varnishes.

Fluoride mouth rinse remains the most widely recommended routine home care oral hygiene due to its anticariogenic properties and ease of 
use. Fluoride mouth rinses are typically based on neutral sodium fluoride solutions ranging from 0.05 to $0.2 \%(225-1,000 \mathrm{ppm})$. Amine and stannous fluoride formulations are also available. ${ }^{(26)}$ Fluoride varnishes are composed of a natural resin, fluoride ions, an organo-phosphoric acid and solvent such as ethanol, also may include proprietary additives in their formulations such as tri-calciumphosphate (TCP), amorphous calcium phosphate (ACP), and xylitol-coated calcium phosphate (CXP). Enamel Pro $^{\circledR}$ Varnish is $5 \%$ sodium fluoride varnish that additionally contains amorphous calcium phosphate (ACP) formula. ${ }^{(27)}$

So the aim of this study is to compare the fluoride release and recharge from new bioactive resin modified glass ionomer compared to conventional glass ionomer cement. The null hypothesis of the study is that there is no significant difference between conventional and resin-modified GICs regarding the fluoride release and recharge.

\section{MATERIALS AND METHODS}

Two glass-ionomer cements were selected (table 1): one CGIC (Fuji IX GP) and a bioactive RMGI (Activa Bioactive). Twenty disc specimens (10 mm diameter x $2 \mathrm{~mm}$ height) of each material were prepared using a split teflon mould according to manufacturer's instructions. After placement of the material in the mould, the surface of the restorative materials was covered with a polyester strip and a glass slab under pressure to expel excess material from the mould. A piece of nylon thread was incorporated into the cement during setting to suspend the samples in the test medium. For RMGI, the polymerization procedure was done through the polyester strip from top and bottom following the manufacturers' instruction, using a light-curing device with light intensity of $500 \mathrm{mw} /$ $\mathrm{cm}^{2}$ (DabiAtlante, RibeirãoPreto, SP, Brazil). The light intensity was controlled at $500 \mathrm{mw} / \mathrm{cm}^{2}$ by measuring with a curing radiometer. All samples were removed from the moulds after $10 \mathrm{~min}$. Specimens were allowed to set for an additional $24 \mathrm{~h}$ in a humid atmosphere at $37^{\circ} \mathrm{C} \pm 1^{\circ} \mathrm{C}$. All specimens were stored at $37^{\circ} \mathrm{C}$ in individually capped, $15-\mathrm{ml}$ polystyrene tubes containing $4 \mathrm{ml}$ deionized water.

Samples were removed from the storing solution, and rinsed with $1 \mathrm{~mL}$ deionized water. Blotting paper was used to remove excess water. Samples were then once more placed in a container containing $4 \mathrm{~mL}$ deionized water, then stored under the same conditions $\left(37 \pm 1^{\circ} \mathrm{C}\right)$. This procedures were repeated every day for one week and then after 15 and 21 days. Daily fluoride release was measured in ppm with ion chromatography. Cumulative fluoride release was calculated for each sample as the total of the amounts of fluoride released during the consecutive elutions. A cumulative release curve against time was then plotted for each group.

TABLE (1) Materials used in the study.

\begin{tabular}{|l|l|l|c|}
\hline \multicolumn{1}{|c|}{ Product } & \multicolumn{1}{|c|}{ Composition } & \multicolumn{1}{c|}{ Manufacturer } & \multicolumn{1}{c|}{$\begin{array}{c}\text { Lot } \\
\text { number }\end{array}$} \\
\hline $\begin{array}{l}\text { Fuji IX GP } \\
\text { (CGIC) }\end{array}$ & $\begin{array}{l}\text { Powder: 95\% by weight fluoro- aluminum silicate glass; 5\% by weight } \\
\text { polyacrylic acid powder } \\
\text { Liquid:40\% polyacrylic acid; 50\% distilled water } \\
10 \% \text { polybasic carboxylic acid }\end{array}$ & $\begin{array}{l}\text { GC } \\
\text { Japan. }\end{array}$ & Corporation, \\
1401131 \\
$\begin{array}{l}\text { Activa Bioactive } \\
\text { (RMGI) }\end{array}$ & $\begin{array}{l}\text { Blend of diurethane and other methacrylates with modified polyacrylic } \\
\text { acid (44.6\%) } \\
\text { Amorphous silica (6.7\%) } \\
\text { Sodium fluoride }(0.75 \%\end{array}$ & $\begin{array}{l}\text { Pulpdent Corporation, } \\
\text { Watertown, MA US }\end{array}$ & 160314 \\
\end{tabular}


After 21 days of first fluoride release, Samples in each group were divided into two equal subgroups $(n=10)$. The samples of subgroup A; were immersed in $0.05 \%$ mouth wash (226 ppm sodium fluoride) for $5 \mathrm{~min}$. Then specimens were washed with $5 \mathrm{~mL}$ of deionized water, air-dried for $1 \mathrm{~min}$, and immersed in individual plastic tubes containing $4 \mathrm{~mL}$ of deionized water at $37^{\circ} \mathrm{C}$. for 5 days, fluoride rerelease measurements were done at 24-h intervals. The samples of subgroup B; were coated with a thin layer of enamel pro varnish $(5 \% \mathrm{Na} F$ varnish, $22.600 \mathrm{ppm} \mathrm{F}$ ) for $2 \mathrm{~min}$. Each sample was returned to a new container filled with $4 \mathrm{~mL}$ fresh deionized water. Fluoride release after recharge was measured and recorded daily.

The fluoride ion was measured using an ion chromatograph (DX 100; Dionex, Camberley, Surrey, UK). Measuring of fluoride ions was made using $0.5 \mathrm{ml}$ of each storage solution which was injected into the injection loop of the instrument. Each solution was examined three times and fluoride concentration measured.

The data was collected, tabulated and statistically analyzed by Two way ANOVA and Duncans test $(\alpha=0.05)$ using the SPSS software program (SPSS version 22, IBM, Chicago, IL, USA).

\section{RESULTS}

\section{Fluoride release}

The results from (Table 2) and (Figure 1) revealed means of daily fluoride release per each material. There was a significant difference of Fluoride-release between CGIC and RMGIC ( $p<$ $0.05)$. Also, it was clear that daily release of fluoride was at maximum level at $1^{\text {st }}$ day and decrease till day seven. That decrease was significant for $1^{\text {st }}$ four days and become less manifested till the end of the $7^{\text {th }}$ day.

From the cumulative fluoride release results (Table 3) and (Figure 2), It was clear that the cumulative fluoride release of CGIC is higher than that of RMGIC. For CGIC, increase in fluoride release was significant between $1^{\text {st }}, 7^{\text {th }}$ and $15^{\text {th }}$ days, while it became not significant between $15^{\text {th }}$ and 21 th day. On the other hand for RMGIC, there was significant increase only between $1^{\text {st }}$ and $7^{\text {th }}$ days.

TABLE (2) Means and standard deviation of each group in ppm and results of Duncans test

\begin{tabular}{|c|c|c|c|c|c|c|c|}
\hline Group/ Days & $1^{\text {st }}$ & $2^{\text {nd }}$ & $3^{\text {rd }}$ & $4^{\text {th }}$ & $5^{\text {th }}$ & $6^{\text {th }}$ & $7^{\text {th }}$ \\
\hline CGIC & $7.08 \pm 0.25^{\mathrm{a}}$ & $4.45 \pm 0.33^{\mathrm{b}}$ & $2.94 \pm 0.23^{\mathrm{c}}$ & $2.09 \pm 0.32^{\mathrm{d}}$ & $1.75 \pm 0.27^{\text {de }}$ & $1.19 \pm 0.17^{\text {ef }}$ & $0.67 \pm 0.13^{\mathrm{f}}$ \\
\hline RMGI & $5.15 \pm 0.29^{\mathrm{a}}$ & $1.86 \pm 0.18^{\mathrm{b}}$ & $0.92 \pm 0.16^{\mathrm{c}}$ & $0.75 \pm 0.19^{\mathrm{d}}$ & $0.56 \pm 0.10^{\text {de }}$ & $0.46 \pm 0 . .06^{\text {ef }}$ & $0.35 \pm 0.13^{\mathrm{f}}$ \\
\hline
\end{tabular}

Means with the same superscripted letters have no significant difference in the same rows

Table 3: Means and standard deviation of cumulative fluoride release in ppm and results of Duncans test.

\begin{tabular}{|c|c|c|c|c|}
\hline Group/Day & $1^{\text {st }}$ & $7^{\text {th }}$ & $15^{\text {th }}$ & $21^{\text {th }}$ \\
\hline CGIC & $7.084 \pm 0.25^{\mathrm{c}}$ & $20.178 \pm 2.12^{\mathrm{b}}$ & $22.90 \pm 1.02^{\mathrm{a}}$ & $24.78 \pm 1.03^{\mathrm{a}}$ \\
\hline RMGIC & $5.15 \pm 0.29^{\mathrm{c}}$ & $10.04 \pm 1.03^{\mathrm{b}}$ & $11.76 \pm 1.01^{\mathrm{ab}}$ & $12.84 \pm 1.68^{\mathrm{a}}$ \\
\hline
\end{tabular}

Means with the same superscripted letters in the same rows had no significant difference 


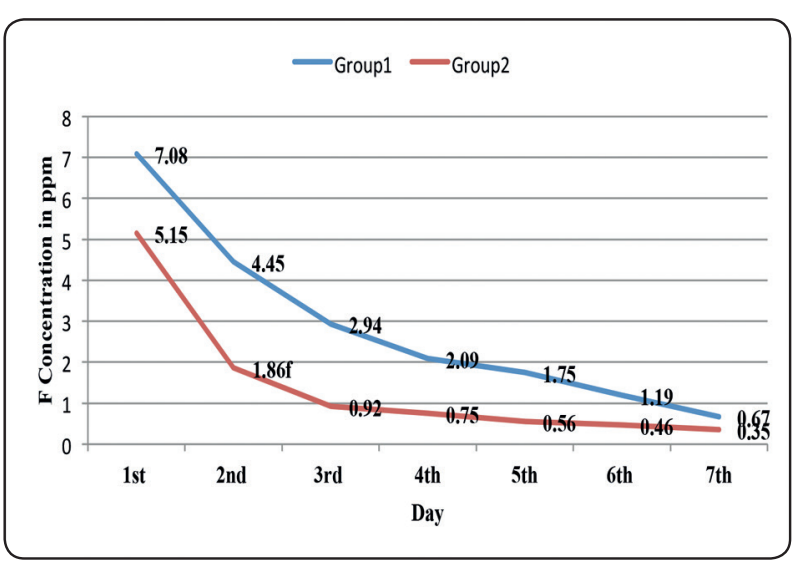

Fig. (1) Daily fluoride release per each material.

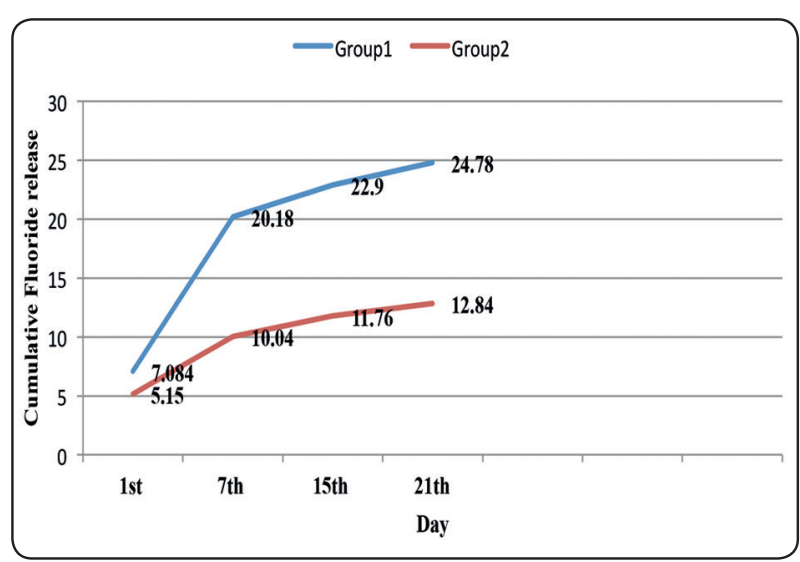

Fig. (2) Cumulative Fluoride release for each material.

Table 4 Means of fluoride re-release after recharge in ppm.

\begin{tabular}{|c|c|c|c|c|c|c|c|c|c|c|}
\hline \multirow{2}{*}{$\begin{array}{c}\text { Group/ } \\
\text { Day }\end{array}$} & \multicolumn{9}{|c|}{ Subgroup A } & \multicolumn{5}{c|}{ Subgroup B } \\
\cline { 2 - 11 } & $1^{\text {st }}$ & $2^{\text {nd }}$ & $3^{\text {rd }}$ & $4^{\text {th }}$ & $5^{\text {th }}$ & $1^{\text {st }}$ & $2^{\text {nd }}$ & $3^{\text {rd }}$ & $4^{\text {th }}$ & $5^{\text {th }}$ \\
\hline CGIC & 3.16 & 0.95 & 0.85 & 0.69 & 0.54 & 7.39 & 4.30 & 3.58 & 1.00 & 0.94 \\
\hline RMGI & 1.87 & 0.68 & 0.60 & 0.54 & 0.35 & 5.42 & 2.64 & 1.90 & 1.58 & 0.63 \\
\hline
\end{tabular}

\section{Fluoride Re-release after recharge}

Table 4 and figure 3 show Means of fluoride re-release after recharge in ppm. Fluoride release from restorative materials after recharging with $5 \% \mathrm{NaF}$ varnish (enamel pro varnish) was higher than fluoridated mouth wash $(0.05 \% \mathrm{NaF})$. Also, it was clear that CGIC had a greater recharge potential than RMGIC.

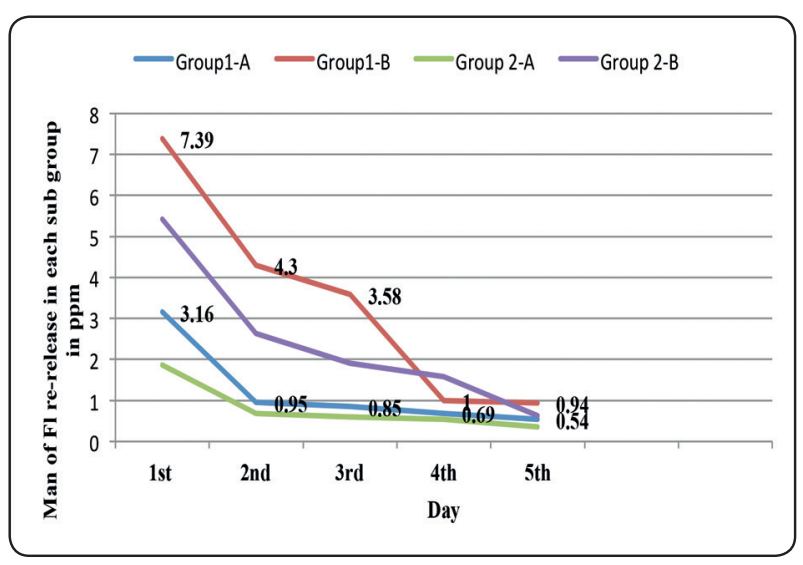

Fig. (3) means of Fluoride re-release after recharge in each subgroup.

\section{DISCUSSION}

Several studies have been done with different results of fluoride release using different materials..$^{(2,28,29)}$ The difference between results may be due to different methods and specimen size, storage media (type and frequency of change), quantity of media used to measure fluoride level. ${ }^{(30)}$ The ideal fluoride-release material should release high fluoride without changing its properties or filling degradation. An initial high level of fluoride release in the majority of restoration will inhibit caries by the bacteriostatic effect of fluoride; more over it induce remineralization of tooth structure. ${ }^{(31)}$

The rate of fluoride release from dental materials can influenced by multiple factors including; storage media, temperature, sample size and powder liquid ratio of the material. ${ }^{(32)}$ The temperature was kept at $37^{\circ} \mathrm{C}$ by placing the samples in an incubator. In addition, the samples were suspended in the storage media by non -fluoridated dental floss allowing uniform wetting of the samples without clinging to the walls of the storage vials. ${ }^{(33)}$ 
Samples were immersed in deionized water to avoid any influence of minerals or organic molecules which might be presented into de/re solutions or saliva. ${ }^{(34)}$ The use of saliva as a storage medium may affect negatively on the results of Ion chromatography .(35) Storage medium was changed every 24 hours as fluoride release is based on a concentration gradient mechanism and when equilibrium is achieved fluoride release is stopped. (36)

Ion chromatograph (IC) used in this study for fluoride detection as it offers lower detection limits (ultra trace levels) and better accuracy. ${ }^{(37-39)} \mathrm{IC}$ also allows the detection of free fluoride ions which are taken up into the tooth. This free fluoride transform hydroxyapatite into fluoroapatite enhancing the resistance of tooth substance to secondary caries. ${ }^{(40)}$

Studied materials released high amount of Fl ions on the first day then the released Fl ions declined sharply but continued to release low amounts of Fl ions throughout the study period. This release pattern is in agreement with previous studies. ${ }^{(41,42)}$ The high release on the 1 st day is induced by the burst of fluoride released from the glass particles when reacting with the polyalkenoate acid during the setting reaction (initial burst) and during the subsequent days release is declined and this is attributed to the dissolution of the glass in the acidified water of the hydrogel matrix and its ability to diffuse through cement pores and fractures(bulk diffusion). ${ }^{(43,44)}$

Our hypothesis is rejected as there was significant difference between CGIC and RMGIC regarding Fl release and recharge. Regarding initial Fl release; CGIC gave higher results than RMGIC which may be attributed to the amount of matrix. ${ }^{(36)}$ For CGIC, the ion released by acid attack at the surface. ${ }^{(22)}$ The acid base reaction is more in CGIC and resulting in thicker matrix in these materials. ${ }^{(36)}$ Initial setting of RMGIC is polymerization reaction followed by an acid base reaction arises from water sorption. ${ }^{(30)}$ The amount of Fl released from RMGIC is affected by amount and type of resin within the material.

Fluoride exposure from external source like varnish or mouth wash can recharge Glass ionomer materials. ${ }^{(22,25,45)} \mathrm{So}$, Glass ionomer restoration can act as an intra-oral device for fluoride slow release. Release of fluoride after topical application depends on the $\mathrm{pH}$, dose, concentration, duration and frequency of application. ${ }^{(46)}$ This study agrees with the results of Takahashi et al., they found that amount of fluoride release proportion with fluoride concentration. ${ }^{(47)}$

Regardless the time and the recharging agent used, CGIC gave higher fluoride release than RMGIC. This may be due to that CGIC has greater glass ionomer matrix. The matrix phase not only promotes fluoride release but also recharging. ${ }^{(36)} \mathrm{Xu}$ and Burgess suggested that high fluoride release material has a higher fluoride recharging ability. ${ }^{(30)}$

Regardless the type of recharging agent, on the $1^{\text {st }}$ day, both restorative materials had an increased amount of fluoride re-release. The fluoride release decrease rapidly suggesting that fluoride release after topical fluoride application represents a washout of ions adsorbed to the surface, rather than an actual diffusion into the matrix. ${ }^{(48)}$

\section{CONCLUSION}

The initial Fluoride release with CGIC was higher than RMGIC. Fluoride varnish ( $5 \% \mathrm{NaF}$ ) has higher recharging ability than mouth rinse $(0.05 \%$ $\mathrm{NaF})$. CGIC can be recharged better than RMGIC.

\section{REFERENCES}

1. Hench LL SR, Allen WC, Greenlee TK Jr. Bonding mechanisms at the interface of ceramic prosthetic materials. Journal of biomedical material research 1971;5(6):117-41.

2. Hicks J, Garcia-Godoy F, Donly K, Flaitz C. Fluoridereleasing restorative materials and secondary caries. Dent Clin North Am 2002;46(2):247-76, vi. 
3. Wilson AD, Kent BE. A new translucent cement for dentistry. The glass ionomer cement. Br Dent J 1972;132(4): $133-5$.

4. Karantakis P, Helvatjoglou-Antoniades M, Theodoridou-Pahini S, Papadogiannis Y. Fluoride release from three glass ionomers, a compomer, and a composite resin in water, artificial saliva, and lactic acid. Oper Dent 2000;25(1):20-5.

5. Ngo H, Mount GJ, Peters MC. A study of glass-ionomer cement and its interface with enamel and dentin using a low-temperature, high-resolution scanning electron microscopic technique. Quintessence Int 1997;28(1):63-9.

6. Forsten L. Short- and long-term fluoride release from glass ionomers and other fluoride-containing filling materials in vitro. Scand J Dent Res 1990;98(2):179-85.

7. Yan Z, Sidhu SK, Carrick TE, McCabe JF. Response to thermal stimuli of glass ionomer cements. Dent Mater 2007;23(5):597-600.

8. Versluis A, Douglas WH, Sakaguchi RL. Thermal expansion coefficient of dental composites measured with strain gauges. Dent Mater 1996;12(5):290-4.

9. Eskandarizadeh A, Parizi MT, Goroohi H, Badrian H, Asadi A, Khalighinejad N. Histological assessment of pulpal responses to resin modified glass ionomer cements in human teeth. Dent Res J (Isfahan) 2015;12(2):144-9.

10. Gladys S, Van Meerbeek B, Braem M, Lambrechts P, Vanherle G. Comparative physico-mechanical characterization of new hybrid restorative materials with conventional glass-ionomer and resin composite restorative materials. J Dent Res 1997;76(4):883-94.

11. Smith DC. Development of glass-ionomer cement systems. Biomaterials 1998;19(6):467-78.

12. manual. ABi. Pulpdent corporation.

13. Mungara J, Philip J, Joseph E, Rajendran S, Elangovan A, Selvaraju G. Comparative evaluation of fluoride release and recharge of pre-reacted glass ionomer composite and nano-ionomeric glass ionomer with daily fluoride exposure: an in vitro study. J Indian Soc Pedod Prev Dent 2013;31(4):234-9.

14. Upadhyay S, Rao A, Shenoy R. Comparison of the amount of fluoride release from nanofilled resin modified glass ionomer, conventional and resin modified glass ionomer cements. J Dent (Tehran) 2013;10(2):134-40.
15. Thuy TT, Nakagaki H, Kato K, Hung PA, Inukai J, Tsuboi S, et al. Effect of strontium in combination with fluoride on enamel remineralization in vitro. Arch Oral Biol 2008;53(11):1017-22.

16. Duggal MS, Chawla HS, Curzon ME. A study of the relationship between trace elements in saliva and dental caries in children. Arch Oral Biol 1991;36(12):881-4.

17. Bruun C, Thylstrup A. Fluoride in whole saliva and dental caries experience in areas with high or low concentrations of fluoride in the drinking water. Caries Res 1984;18(5):450-6.

18. Sjogren K, Birkhed D. Factors related to fluoride retention after toothbrushing and possible connection to caries activity. Caries Res 1993;27(6):474-7.

19. Featherstone JDB ZDLahstetmoaof-cdIEG, Rølla G, editors. Clinical and biological aspects of dentifrices. New York: Oxford University Press; 1992. p. 41-50.

20. Preston AJ, Higham SM, Agalamanyi EA, Mair LH. Fluoride recharge of aesthetic dental materials. J Oral Rehabil 1999;26(12):936-40.

21. Han L, Cv E, Li M, Niwano K, Ab N, Okamoto A, et al. Effect of fluoride mouth rinse on fluoride releasing and recharging from aesthetic dental materials. Dent Mater J 2002;21(4):285-95.

22. Vermeersch G, Leloup G, Vreven J. Fluoride release from glass-ionomer cements, compomers and resin composites. J Oral Rehabil 2001;28(1):26-32.

23. Walls AW, McCabe JF, Murray JJ. The effect of the variation in $\mathrm{pH}$ of the eroding solution upon the erosion resistance of glass polyalkenoate (ionomer) cements. Br Dent J 1988;164(5):141-4.

24. De Witte AM, De Maeyer EA, Verbeeck RM, Martens LC. Fluoride release profiles of mature restorative glass ionomer cements after fluoride application. Biomaterials 2000; 21(5):475-82.

25. Diaz-Arnold AM, Holmes DC, Wistrom DW, Swift EJ, Jr. Short-term fluoride release/uptake of glass ionomer restoratives. Dent Mater 1995;11(2):96-101.

26. Tehrani MH, Asghari G, Hajiahmadi M. Comparing Streptococcus mutans and Lactobacillus colony count changes following green tea mouth rinse or sodium fluoride mouth rinse use in children (Randomized double-blind controlled clinical trial). Dent Res J (Isfahan) 2011; 8(Suppl 1): S58-63. 
27. Skrtic D, Hailer AW, Takagi S, Antonucci JM, Eanes ED. Quantitative assessment of the efficacy of amorphous calcium phosphate/methacrylate composites in remineralizing caries-like lesions artificially produced in bovine enamel. J Dent Res 1996;75(9):1679-86.

28. Francci C, Deaton TG, Arnold RR, Swift EJ, Jr., Perdigao $\mathrm{J}$, Bawden JW. Fluoride release from restorative materials and its effects on dentin demineralization. J Dent Res 1999;78(10):1647-54.

29. Momoi Y, McCabe JF. Fluoride release from light-activated glass ionomer restorative cements. Dent Mater 1993;9(3):151-4.

30. Mousavinasab SM, Meyers I. Fluoride release by glass ionomer cements, compomer and giomer. Dent Res J (Isfahan) $2009 ; 6(2): 75-81$.

31. Freedman R, Diefenderfer KE. Effects of daily fluoride exposures on fluoride release by glass ionomer-based restoratives. Oper Dent 2003;28(2):178-85.

32. Verbeeck RM, de Moor RJ, Van Even DF, Martens LC. The short-term fluoride release of a hand-mixed vs. capsulated system of a restorative glass-ionomer cement. J Dent Res 1993;72(3):577-81.

33. Swartz ML, Phillips RW, Clark HE. Long-term F release from glass ionomer cements. J Dent Res 1984;63(2): 158-60.

34. Garcez RM, Buzalaf MA, de Araujo PA. Fluoride release of six restorative materials in water and $\mathrm{pH}$-cycling solutions. J Appl Oral Sci 2007;15(5):406-11.

35. Whitford GM, Thomas JE, Adair SM. Fluoride in whole saliva, parotid ductal saliva and plasma in children. Arch Oral Biol 1999;44(10):785-8.

36. Itota T, Carrick TE, Yoshiyama M, McCabe JF. Fluoride release and recharge in giomer, compomer and resin composite. Dent Mater 2004;20(9):789-95.

37. Yap AU, Khor E, Foo SH. Fluoride release and antibacterial properties of new-generation tooth-colored restoratives. Oper Dent 1999;24(5):297-305.
38. McCabe JF, Carrick TE, Sidhu SK. Determining low levels of fluoride released from resin based dental materials. Eur J Oral Sci 2002;110(5):380-4.

39. Gedalia I, Mayer I, Giron J, Deutsch D. Fluoride deposition in the bones of rats determined by fluoride and X-ray diffraction analysis. Arch Oral Biol 1982;27(10):823-5.

40. Meurman JH, Hemmerle J, Voegel JC, Rauhamaa-Makinen R, Luomanen M. Transformation of hydroxyapatite to fluorapatite by irradiation with high-energy $\mathrm{CO} 2$ laser. Caries Res 1997;31(5):397-400.

41. Grobler SR, Rossouw RJ, Van Wyk Kotze TJ. A comparison of fluoride release from various dental materials. J Dent 1998;26(3):259-65.

42. DeSchepper EJ, Berr EA, 3rd, Cailleteau JG, Tate WH. A comparative study of fluoride release from glass-ionomer cements. Quintessence Int 1991;22(3):215-9.

43. Forsten L. Fluoride release and uptake by glass-ionomers and related materials and its clinical effect. Biomaterials 1998;19(6):503-8.

44. De Moor RJ, Verbeeck RM, De Maeyer EA. Fluoride release profiles of restorative glass ionomer formulations. Dent Mater 1996;12(2):88-95.

45. Helvatjoglu-Antoniades M, Karantakis P, Papadogiannis Y, Kapetanios H. Fluoride release from restorative materials and a luting cement. J Prosthet Dent 2001; 86(2):156-64.

46. Dhull KS, Nandlal B. Comparative evaluation of fluoride release from PRG-composites and compomer on application of topical fluoride: an in-vitro study. J Indian Soc Pedod Prev Dent 2009;27(1):27-32.

47. Takahashi K, Emilson CG, Birkhed D. Fluoride release in vitro from various glass ionomer cements and resin composites after exposure to NaF solutions. Dent Mater 1993;9(6):350-4.

48. Rothwell M, Anstice HM, Pearson GJ. The uptake and release of fluoride by ion-leaching cements after exposure to toothpaste. J Dent 1998;26(7):591-7. 